\title{
The influence of visual representations of "the Other" in the system of modern sociocultural communications
}

\author{
Nataliya Kolodii ${ }^{1, \mathrm{a}}$, Vyacheslav Kolodii ${ }^{1}$, Nataliya Goncharova ${ }^{1}$, and Alyona Ivchik ${ }^{1}$ \\ ${ }^{1}$ National Research Tomsk Polytechnic University, 30 Lenin Ave., Tomsk, 634050, Russia
}

\begin{abstract}
The paper deals with the way and the form of modern humanitaristics understanding of the problem of visual representation of "the Other". The authors' tasks were to comprehend the nature and dynamics of visualization, to give a distinct working definition of visual competence. Besides, the purpose of the paper was to state the components of visual competence, its criteria, estimation methods and in this context to interpret the image of "the Other" decoded in scientific philosophic and cultural literature and in daily cultural practices. And the final task was to reduce the visual message to the verbal one. The doctrine that the image may be read is the common prejudice, which prevents the formation of a new approach to visuality. The first step towards the solution of problem is to describe the techniques, which help in potential understanding of the visual structure. Understanding the image diversity and its possible text analogues should help in establishing the specific requirements, which can be and must be applicable to visual representation of "the Other". Representations in the visual culture (photography, cinematography, media, painting, advertisement) influence the social image, affects the daily social practices and communications. Visual representations are of interest for social theorists as well as cultural texts, as they give an idea on the context of cultural production, social interaction and individual experience.
\end{abstract}

\section{Introduction}

The relevance of the topic is related to several circumstances. Firstly, the authors' ideas on "the Other" were mainly defined for a long time by the principles of political correctness and the philosophy of multiculturalism. Nowadays these principles in humanitarianism turned out to be in a suspicion discourse zone and it is impossible to follow these principles in daily cultural practices. Secondly, it turned out that institutionalization of "the Other" is not only the topic of social-anthropological, politological, philosopho-cultural studies, but it is as well a real cultural practice appealing actively to visual images, which should be analyzed.

In modern philosophy the occurrence of the "visual" subject may be certainly found out within (post)structuralism, first of all, in the works of $P$. Bourdieu, R. Bart, M. Foucault et al. [1, 2, 3]. Social theorists have paid attention initially to the photographic idea of "the Other" and to the reflection of different ideologies and control strategies, power microphysics in visual representations.

A new surge in studying the visual structure is observed in the beginning of the 1990-s both in anthropological and in sociological discourses. A great amount of articles, special issues resulted in lively

\footnotetext{
a Nataliya Kolodii: kolna@tpu.ru
}

discursive discussion of visual practices as a set of interdisciplinary researches. The visual representations as the instrument for criticizing the existing system were subjected to special problematisation. E. Chaplin, the author of the book "Sociology and Visual Representation", proved that a photo (a center of visuality) may be considered not only as the method of capturing data, but as the medium transferring and creating new knowledge [4].

In modern cultural and philosophic literature (J. Alexander, M. Bal, R. Garland-Thomson, J. Crary, M. Jay, K. Moxey, J.-L. Nancy, L. Mulvey, J. Ruby) there is the release into the topic of philosophic anthropology: the model of a "photographic person" is built. It includes the most significant traits of the modern person $[5,6,7$, $8,9,10,11,12,13,14]$. Owing to the researches of these authors, the idea that visual studies form the knowledge not about visuality, but by means of the latter, is confirmed. Inside this optics several old ideas and oppositions, which were reproduced with respect to this phenomenon, become irrelevant.

The main aim of the research is to determine the level of effect of visuality, or more precisely the visual representation of "the Other", on the whole system of socio-cultural communications.

The tasks are: 
1. to characterize the principles of creating visual representations of "the Other" within the visual turn and increased visual competence;

2 . to determine the system of circumstances and factors defining the image of visual "the Other";

3. to find out the specific character of visual practices, their relation to the dominant ideological projects, their historical determinacy, formal and esthetic aspects and content transformations of visual representations of "the Other".

\section{Methods}

Methodological principles:

1. Principles of the constructivist approach to the phenomenon "representation", which suppose that the meaning is not specified and it does not exist before the representation, but it is constructed at prefiguration.

2. Representation is not the reflection. It is more likely the active process of selecting and representing, structuring and forming, it is the process of investing something with sense.

3. Social dimension is built-in the process of creating visual representations, as they are always a certain selfdemonstration to "the Other" according to the ideas about "the Other" and expectations of "the Other".

4. Therefore, social cognition, interpreting this dimension, becomes the other as minimum and more extended and catching the variety of the reality as maximum.

There is a circumstance, which prevents the comprehension of the central problem of the research, a new method of representation of "the Other" in current conditions. It is the impossibility of synthesizing all effects, findings of visual turn, visual anthropology, which are piecewise described and interpreted in modern humanitarian, philosophic, social and cultural thought.

The authors try to single out the most valuable methodological constructions, which were the base of this new method of representation. The authors break the chronological principle of occurrence of these intuitions here and they will not be sequentially interpreted. These intuitions are synthesized and assimilated by a modern individual and modern culture even if the latter does not self-reflect sufficiently about agreements and conventions determining the practice of vision in modern culture. The methodology, used by the authors, is close to the principles of modern researcher N. Bryson. The authors rely on the assumption concerning the fact that the dense net of particular visual matrices is created by the culture between an individual and the reality. These matrices construct the visual regime, a certain cultural construct, which makes vision different from sense of vision, that is physiological, direct empirical emotion [15]. N. Bryson considers, and the authors are at one with the researcher, that between the retina and the world, there is "screen of signs" inserted between retina and the world, a "screen" consisting of symbols, figures, fragments of discursive formations, perspectives, defining a vision in a particular socio-cultural environment. In all circumstances an individual is forced to decipher, decode the cultural world she/he is surrounded by, and so conventions, agreements, social consensuses are accepted, and there appears the possibility of organic existence within a complex system of signs, symbols $[15,16]$.

Let us reflect on whether the visual turn in culture has happened and what accents were brought by the visual representations into ideas on "the Other". There is no the absolute answer.

\section{Results \& discussion}

Positions of those authors, who confirm that the turn has happened, is based on the fact that visual reality (including automatisms of visual perception in the daily life) appears as the modern social construct which is subjected to "reading" and interpretation to the same degree as philosophical text or a book, which totally define the modern cultural experience of an individual. Visuality is not any more perceived as the secondary dimension of cultural practice (M. Banks, K. Moxey). But it gives another ideas on "the Other": as on an individual endowed with different corporality, different habitus, different practice of life $[17,11]$. The opposite position (Jansson A.) recognizes the visuality as the dominant cultural phenomenon, but not as the one suppressing all the other cultural practices. According to this approach, the visuality brings no significant shifts into the idea on "the Other" [18].

In the current situation the experts in the field of classical art, appropriating traditionally the right to interpret visual representations, make a way for a new wave of theorists in the field of visual communications (D. Elkins). These very theorists must clear up the situation with the visual representation of "the Other" [19].

Study of visuality in a broad sense should include the analysis of non-European cultural practices of vision, techniques and conventions of visual representation and artistic figurativeness as they broaden significantly the idea on "the Other".

It is telling that the postnonclassical philosophy - the sphere of pure Logos - became one of the first humanitarian subjects, having realized the necessity of understanding our being-in-the world-of visual culture. Especially that the philosophic analysis of prerequisites and conditions of thinking process, consciousness phenomenon, memory and storage mechanisms, subjectivity formation, perception automatisms were initially based on the data of visual experience and used the visual categories: image, "world view", "space", "form", "images of consciousness", "imagination", "intelligent contemplation", "speculation" etc. These philosophical metaphors seem to be "neutral" in the world of philosophic abstractions: more often their visual status is not taken into consideration; they are used as rhetorical constructs reflecting a certain essence of the withdrawn being. However, it is possible to refer to visuality, studied by the west philosophic tradition, in different terms: it may be interpreted as the evidence of 
visual culture rootedness in logo-centrist discourse of metaphysics [9]. The following questions: Are visual images the guides of non-verbalize sense? Can they be conceived by other means than language? Is the linguistic form obligatory for expressing our visual experience? Is the visual language autonomous? What is the "image"? Are all images visual? In what way does image function in consciousness, in memory, in imagination? What is the ratio of art and other forms of visual culture? What does remain in visual culture except the verbalized information? To which degree does the development of visual techniques affect the essence of visual practices?

Non-European thinkers have the fundamentally different questions: Whether visual representations, developed in European culture, broaden or not our ideas on "the Other" otherness? Or do we need the visuality forms of different non-European types, different rationality types, different ways of cultural being?

Many researchers state the idea that the increased visual information makes it difficult to be guided in it; it requires new tactics and procedures of understanding. This is the reason why the topic of visual competence subject, which is comprehended as a capacity for situationally specified interpretation of visual information, is relevant, especially in the field of understanding the visual "the Other".

Nowadays we can see much more amount of "patterns", images during a month and a year than people can see in the past. Moreover, visual information grows exponentially - visual advertisement becomes more advanced. Therefore, a man, living in such visually saturated world, has to be more visually learned than a man of all previous epochs was. She/He should develop her/his capacity for comprehending a great amount of heterogeneous visual information.

This simple observation is proved by the studies of D. Crary, devoted to the transience and fragmentary nature of modern attention [8]. The source of this very capacity, in the author's opinion, is the necessity to perceive simultaneously a large amount of pictures and the capacity of changing quickly to new information. The author confirms, that our incapacity to a long-term continuous observation of a picture, which was left in 19 century, changes the style of observation and the style of painting, the type of popular repose and the style of working day management [8]. This type of disordered urbanistic observer (flaneur), described for the first time by $\mathrm{Ch}$. Baudelaire, was caught up by W. Benjamin. In the concepts of the latter this character became the dominant figure for the type of our sociality [20]. The same type represented the visual "the Other" for a long time.

Our time is a more visually educated period, which forms certain "scopic regimes" by M. Jay; the beginning of the XXI century may be identified as exaggerated extension of the regime, which was called the Cartesian perspectivism. Within this vision regime, a great amount of information may be unprecedentedly assimilated [9]. M. Jay confirms that modern capacity to perceive visual information may be considered as "baroque" type of observation with its disorder and complexity [9].
Logically the cultures, which are included into the concept of scopic regime, contain more knowledge on visuality, on visual forms, on structures, on visual representations of "the Other".

Another version of the above-mentioned visual competence claim comes from dichotomy between visuality and verbality. For example, N. Mirzoeff confirms that "Western philosophy and science uses now an iconic world model rather than the textual one, challenging the statement that the world is like a written text and it may be studied as a text" [21]. The book of K. Sachs-Hombach, K. Rehkamper, devoted to the philosophy of painting, starts with the statement that "we live in visual century: in the century of images. Images represent the information, serve as a link between the information, make it comprehensible, clear, understandable" [22]. The explicit version of this statement belongs to D. Chaney [23]. He confirms that, firstly, that new media creates "the role of pictures in daily life discourses", secondly, that "the paradigm shift" from metaphorical to discursive thinking took place. The third circumstance, which was emphasized by the author, is that mass tourism spreading increases the importance of "peculiar view", encourage of consumer interest and appropriation. The forth idea, developed by the author, is that there was a turn in "methods of embodying (imaging)" resulting in test of other senses by active observation; and, fifthly, knowledge of constitutive meaning of the gender component increased [23]. Therefore, the visual competence allowed at least «reading» adequately gender features and gender otherness. Some thinkers developed these engendered ideas on visual "the Other" in the researches devoted to visual daily practices. Marita Sturken and Lisa Cartwright start their book "Practices of Looking: an Introduction to Visual Culture" with the statement that western culture in two last centuries became dominant by visuality rather than oral or textual media. "Visual culture is central to how we communicate. Our lives are dominated by images and by visual technologies that allow for the local and global circulation of ideas, information, and politics" [24].

There is, however, the contrary opinion, that the twenties century should be considered as absolutely nonvisual. The reason of this consists in the fact that the key philosophic conceptions, which were developed that time, did not refer directly to visuality or opposed themselves clearly to the visuality culture. M. Jay introduces this argument rather definitely in the book, where he analyzes structuralistic and poststructuralistic texts discussing the ideas of observation and visuality [9]. Analysis of M. Jay is reduced to the fact that approaches and views of M. Heidegger, J. Lacan, J. Derrida and even M. Merleau-Ponty, who criticized the ocular-centralism of western-European thinking, are non-visual to a certain extent, that is they tend to verbal discourses. Within the "post-ocular theory", the multiple attempts to shift aside from visual metaphor dominance were made. Similar projects may be represented by the criticism of mirror metaphor of Richard Rorty in western philosophy and various literary philosophies from L. Wittgenstein to M. Bachtin. Anti-ocular-centralism 
could become to some extent the necessary project operating against the ocular metaphor, which has led to western metaphysics. If the modern era is non-visual, all ideas about different "the Other" is only additions to philosophic discourse on "the Other".

B. Stafford develops these ideas [25]. She states that we have learned successfully to understand the variable pictures and lost the type of visual competence, which gives the opportunity to understand "the Other" and requires more complex algorithm of interpreting compound visual images, which become non-visual for us. Our recently acquired capacity "to interpret" and to decode such images does not compensate the destruction of our capacity to understand more personalized (author's) and more intractable works of the previous centuries. B. Stafford notes that it is rather natural for pre-modern graphics not to be accessible for rapid interpretation; perception was aimed at some time. B. Stafford gives an example of Heinrich Khunrath works, representing mystic actions in alchemic theatre laboratory of the 17 century. They represent the idea of "interpreting carefully" or "decoding" the images, coming back to them many times, thinking over slowly separate details, building gradually the senses. It is really the representation of the laboratory in its nature: in orthodox interpretation it is the place for working, producing sense and the place for service. The image of Christianity, represented in a hermeneutic manner by the artist, requires studying the picture for months and years, getting the ideas and associations out of it, thus carrying out something like alchemic work [25].

All above-mentioned positions are rather sound, and even one cannot agree with them relative to their attitude to visuality it is necessary to take into account the authors argumentation concerning perception and interpretation of visual "the Other".

Visual anthropology develops other approaches to the problem of visual representation of "the Other". The authors will not study all aspects of this new research strategy, but will concentrate on those "investments" into social cognition, which it has made. Let us consider as well those threats and risks, complexities in social cognition, which have been determined due to the visual anthropology; and those achievements, which we have.

In visual anthropology, a subject (author, researcher) abandons the position of a distant observer of some external scene, armed her/himself with special conceptual, ideological and technical optics, which allows holding safe "cognitive" distance from the scene. She/He abandons as well the asymmetric educating comment even if this refers to non-Europeanized "the Other". Visual anthropology opens visual sense enforcement to "self-display", to obtain the visibility and accessibility for analysis [26].

The visual anthropology proved that "third world" was modernized during colonization and neocolonization. "Aboriginal world" became a particular superconductor for western marketing strategies and media information streams. The mechanisms of "power/knowledge" formatted traditional cultures for needs of the global market [3]. This very trend of situating a spectator (post-modern consumer) into position of vision comes to the fore. In this position the implicit value valorization of "first world" is added with the function of visual entertainment. "The Other" falls into "funny pictures", in which its nonsense of otherness is emphasized, "the Other" starts functioning as a phreak in TV show. Thus the ethnographic film is assimilated by mass-media space and turns it into "minor subset of the commercial documentation world", a supplier of video-production for the net of public television PBS in the USA, global National Geographic etc. [27, 28].

Visual anthropology and sociology try to avoid the simplified technologies of understanding visual "the Other". Interpreting the features of visual representation of "the Other" they develop more adequate approaches. The most fruitful approach, in our opinion, we can see in the works of S. Hall. The researcher considers it possible to reduce the variety of theoretical approaches in solving this problem to three main models of interpretation: reflective (mimetic), intentional and constructivist (including semiotic and discursive approaches). S. Hall defines representation as a process for using a language (any sign system) by a subject to make meanings. The objects of representation do not possess the meaning, the sense is born in interpretation and communication, coding and decoding of texts and depends of the cultural context [29]. These principles and this methodology seem to be the very important instruments, which can be the reliable orientation in perceiving visual representation of "the Other"; as well as the adequate experience in decoding the multiple senses possessed by a visual source.

\section{Results}

In visual representations, visual research (in comparison with the text narratives) emphasizes most of all "otherness of the Other" and sees the territory of selfsufficient otherness in it, which does not belong to anyone, and then decodes it. One of the arguments of criticizing the simulation of "the Other" existence, which is supported by the effective linguistic mechanism, consists in ensuring by such simulation only the illusion of "the Other" presence in the discourse. Moreover, the researchers of visual forms, criticizing rightly the practice of simulating the existence of "the Other", propose the real possibility to understand "the Other" in its "real otherness" by adequate analysis of visuality. "Actualization of the Other" and responsibility for this "the Other" is the base of the project of the future reflected by the visual representations. Visual representations of "the Other" allow making communications symmetric without conjecturing for "the Other", without enforcing proper rationality and proper logic on her/him.

\section{References}

1. P. Bourdieu, Photography: A Middle-brow Art. (Stanford, CA: Stanford University Press, 1990)

2. R. Barthes, Camera Lucida: Reflections on Photography (Farrar, Straus and Giroux, 1981) 
3. M. Foucault, Discipline and Punish: The Birth of the Prison (New York: Pantheon, 1977)

4. E. Chaplin, Sociology and Visual Representation. (London: Routledge, 1994)

5. J. Alexander, Iconic Experience in Art and Life. Theor. Cult. Soc., 25 (5), (2008)

6. M. Bal, J. Vis. Stud., 2(1), (2003)

7. R. Garland-Thomson, J. Vis. Cult., 5(2), (2006)

8. J. Crary, The Techniques of Observer: On Vision and Modernity in the 19th Century (Cambridge, MA: MIT Press, 1992)

9. M. Jay, Scopic Regimes of Modernity. In Vision and Visuality (Seattle, WA: Bay Press, 1988)

10. M. Jay, Vision in Context: Reflections and Refractions (Routledge, 1996)

11. K. Moxey, J. Vis, Cult. Los Angeles, London, New Delhi and Singapore: Sage, 7 (2), (2008)

12. J.-L. Nancy, The Ground of the Image (New York: Fordham University Press, 2005)

13. L. Mulvey, Visual pleasure and narrative cinema. In Visual Culture: the Reader (Eds. Jessica Evans and Stuart Hall. London: Sage Publications, 1999)

14. J. Ruby, Visual Anthropology. In D. Levinson, \& M. Ember (Eds.), Encyclopaedia of Cultural Anthropology (New York: Henry Holt and Company, 1996)

15. N. Kolodii, V. Kolodii, Y. Chayka, \& N. Goncharova, Procedia - Soc. Behav. Sci., (2015)

16. N. Bryson, Vision and Painting: The Logic of the Gaze. (U.P. Vale, 1983)

17. M. Banks, Visual methods in social research (London: Sage, 2001)

18. A. Jansson, Textural Analysis. Materialising Media Space. In Geographies of Communication: The Spatial Turn in Media (Göteborg, 2006)

19. D. Elkins, Visual Studies: a Skeptical Introduction (London, NY: Routledge, 2003)

20. W. Benjamin, The Work of Art in the Age of Mechanical Reproduction. (New York: Schocken Books, 1969)

21. N. Mirzoeff, Visual Culture Reader (London: Routledge, 1999)

22. K. Sachs-Hombach \& K. Rehkamper, Einleitung. In Bild - Bildwahrnebeitung. Wiesbaden: Deutscher Universitats-Verlag, (1998)

23. D. Chaney,. Theor. Cult. Soc., (2000)

24. M. Sturken, L. Cartwright, Practices of Looking: An Introduction to Visual Culture (N.Y., Oxford: Oxford University Press, 2009)

25. B. Stafford, Good Looking: Essays on the Virtue of Images (Cambridge, MA: MIT Press, 1996)

26. W.J.T. Mitchell, J. Vis. Cult., 1(2), (2002)

27. J. Urry, The Tourist Gaze: Leisure and Travel in Contemporary Societies. London: Sage, (1990)

28. A. Grimshaw, The eye in the door; anthropology, film am the exploration of interior space (Yale University Press: Wiltshire, 1999)

29. S. Hall, The Work of Representation. In Representation: Cultural Representations and Signifying Practices (The Open University: Milton Keynes, 1997) 